\title{
A África nos filmes infantis: uma análise de Madagascar
}

\author{
Africa in children's films: an analysis of Madagascar \\ África en películas infantiles: un análisis de Madagascar
}

\begin{abstract}
Maria CAROlina da Silva CAldeira*
$\diamond$

RESUMO - Este artigo tem como objetivo analisar que representações sobre a África e os africanos são divulgadas pelos filmes infantis de animação Madagascar 1 e 2. Com inspiração na vertente pós-estruturalista dos estudos culturais em educação, considera-se que esses filmes exercem uma pedagogia cultural, a qual ensina e constrói representações desse continente. O argumento desenvolvido é o de que esses filmes, ao representarem a África, atualizam o binarismo entre natureza e cultura, associando a África à natureza e as grandes metrópoles à cultura. Nesse processo, o polo natural é considerado inferior ao polo cultural. Por meio de relações de poder desiguais, aqueles que habitam o continente africano também são considerados inferiores aos habitantes de outras regiões. Dessa forma, os filmes se inserem em um longo processo performativo que repete representações historicamente construídas sobre a África, as quais a situam como um continente exclusivamente selvagem, perigoso e habitado por seres exóticos.
\end{abstract}

Palavras-chave - África. Representação. Pedagogia cultural. Estudos culturais.

ABSTRACT - This Article has as objective to analyze which Africa and the Africans representations are disclosed by children's films animation Madagascar 1 and 2. Inspired by the strand post-structuralist analysis of cultural studies in education, it is considered that these movies exert a cultural pedagogy, which teaches and builds representations of this continent. The argument developed is that these movies, to represent Africa, update the dual between nature and culture, associating Africa to the nature and the large metropolises to culture. In this process, the natural pole is considered inferior to the cultural pole. Through unequal power relationships, those who inhabit this continent are also considered lower than the inhabitants of other regions. In this way, the films fall in a long performative process that repeats representations historically constructed about Africa, which are located as a continent exclusively wild, dangerous and inhabited by exotic beings.

Keywords - Africa. Representation. Cultural pedagogy. Cultural studies.

RESUMEN - Este artículo tiene por objetivo analizar las representaciones de África y de los africanos que son revelados por las películas de animación Madagascar I y II. Inspirado en el capítulo post-estructuralista los estudios culturales en el ámbito de la educación, se considera que estas películas tienen una pedagogía cultural, que le enseña y construye representaciones de este continente. El argumento es que estas películas, para representar a África, actualizam lãs oposiciones entre la naturaleza y la cultura, asociando el África a la naturaleza y las grandes ciudades de la cultura. En este proceso, el polo natural se considera inferior al centro cultural. Gracias a las relaciones desiguales de poder, quienes habitan este continente también son considerados inferiores a los habitantes de otras regiones. De esta manera, la oferta de las películas se vuelven parte de un largo proceso performativo las representaciones que se repite históricamente construidas sobre África, que son como un continente exclusivamente en el medio silvestre, peligroso y habitado por seres exóticos.

Palabras clave - África. Representación. Pedagogía cultural. Los estudios culturales.

\footnotetext{
* Doutoranda em Educação pela Universidade Federal de Minas Gerais (Belo Horizonte, Minas Gerais, Brasil) e Professora do Centro Pedagógico na Universidade Federal de Minas Gerais (Belo Horizonte, Minas Gerais, Brasil). E-mail: <mariacarolinasilva@hotmail.com>.
} 


\section{INTRODUÇÃO}

A Lei 10639/2003 que instituiu o estudo de História e Cultura Africana e Afro-Brasileira nas escolas de ensino fundamental e médio do Brasil significou um importante avanço nas discussões acerca da inclusão de diferentes grupos étnico-raciais nos currículos escolares. Com o objetivo de reverter o quadro histórico de exclusão dos conhecimentos dos grupos não brancos no contexto escolar, a Lei constitui um mecanismo de ação afirmativa (GOMES, 2008), pois pretende dar visibilidade àqueles grupos que foram excluídos ao longo do tempo. Por meio dessa Lei, intenciona-se reverter a "grande desinformação sobre a nossa herança africana e sobre as realizações do negro brasileiro da atualidade" (GOMES, 2008, p. 74).

Seu objetivo é construir outra representação do continente africano, uma representação que não o retrate "de forma secundária, associado ao périplo marítimo dos séculos XV e XVI, ao tráfico de escravos e aos processos históricos do Imperialismo, Colonialismo e das Independências na África" (OLIVA, 2009, p. 144), mas que apresente o continente em sua totalidade, riqueza e importância. Em função dessa legislação, houve alteração nos livros didáticos e nos materiais usados para orientar os trabalhos realizados em sala de aula, bem como construção de projetos por parte dos docentes com o objetivo de garantir essa efetivação. Sendo assim, é possível notar no contexto brasileiro atual uma tentativa de garantir que histórias diferentes sobre o continente africano sejam contadas em sala de aula.

Essas tentativas esbarram, porém, em questões estruturais da escola, tais como a falta de recursos para implementar propostas ou ainda em preconceitos por parte dos profissionais da educação, que consideram que a questão étnico-racial refere-se exclusivamente aos negros ou que essa Lei realiza um racismo às avessas (GOMES, 2008). Aliadas a esses fatores, há outras questões que também dificultam a construção de outra visão sobre a África, tais como o modo como esse continente é narrado em diferentes artefatos culturais. Esse último aspecto se constitui no foco deste artigo. Analiso aqui como um artefato cultural contemporâneo - os filmes de animação Madagascar 1 e 2 - constroem narrativas sobre a África que vão na contramão daquilo que a legislação educacional brasileira determina como fundamental para contar outras histórias sobre esse continente.

Os dois filmes foram lançados pelos Estúdios DreamWorks, respectivamente, em 2005 e 2008, e contam a história do Leão Alex, do hipopótamo Glória, da girafa Melman e da zebra Marty. Os quatro vivem no zoológico de Nova York, mas após uma série de incidentes vão parar na ilha de Madagascar no primeiro filme. No segundo, eles tentam escapar da ilha, porém o avião em que estavam cai no continente africano. As duas animações foram sucessos de bilheteria, sendo que a primeira delas arrecadou cerca de 532.680.671 e a segunda 603.900 .354 dólares. $^{1}$ Além dos dois filmes aqui analisados, há um terceiro, lançado em 2012, ${ }^{2}$ uma série de desenhos animados para a televisão (Os pinguins de Madagascar) e produtos variados com os personagens dos filmes, como brinquedos, roupas, materiais escolares, jogos de videogame, entre outros, o que mostra a forte presença desse artefato cultural em diferentes espaços.

Com base nos estudos culturais, os filmes de animação aqui analisados praticam uma pedagogia cultural ou possuem um currículo cultural. As noções de pedagogia e currículo cultural partem do pressuposto de que, na atualidade, a educação ocorre em "uma variedade de locais sociais, incluindo a escola, mas não se limitando a ela" (STEINBERG, 1997, p. 101-102). Artefatos como programas de televisão, músicas, jogos, revistas em quadrinhos, internet, filmes, livros diversos, campanhas publicitárias são considerados diretamente envolvidos no processo educativo das pessoas. Sendo assim, esses artefatos "transmitem uma variedade de formas de conhecimento que, embora não sejam reconhecidos como tais, são vitais na formação de identidades e subjetividades" (SILVA, 2001, p. 140). Neste trabalho, analiso que representações da África e dos seres que a habitam são divulgadas por meio dos filmes Madagascar 1 e 2. O argumento aqui desenvolvido é o de que essas representações atualizam o binarismo entre natureza e cultura que marca parte da cultura ocidental. Nesse processo, o polo natural (representado pela África) é considerado inferior ao cultural (representado pelas cidades, particularmente por Nova York). Por meio de relações de poder desiguais, os habitantes do continente africano também são considerados inferiores aos de outras regiões. Dessa forma, os filmes se inserem em um longo processo performativo que repete representações historicamente construídas sobre a África, as quais a situam como um continente exclusivamente selvagem, perigoso e habitado por seres exóticos.

Para analisar os filmes em questão, foi utilizada como metodologia a etnografia da tela, termo utilizado por Rial (2005, p. 120) e que "transporta para o estudo do texto da mídia procedimentos próprios da pesquisa antropológica”, aliando-os à análise de aspectos cinematográficos. Assim, para a análise, foram utilizados procedimentos da etnografia, como "longo período de contato com o campo [neste caso, com a tela], observação sistemática e variada; registro em caderno de campo; escolha de cenas para análise propriamente dita" (BALESTRIN; SOARES, 2012, p. 93). Além disso, fiquei atenta aos aspectos da 
linguagem cinematográfica, tais como fotografia, trilha sonora, diferentes tipos de plano, opções de montagem, entre outros. Todos esses elementos foram fundamentais para compreender como circulam as representações do continente africano nos artefatos culturais analisados.

Para mostrar de que forma os filmes analisados operam na construção de representações da África e dos africanos, este artigo está dividido em quatro partes. Na primeira, apresento o referencial teórico do trabalho, mostrando como os conceitos de representação e performatividade foram desenvolvidos no trabalho. $\mathrm{Na}$ segunda, analiso como a África é associada a uma visão de natureza idílica e idealizada em oposição à metrópole, apresentada como cultural e caótica. Em seguida, discuto como são apresentados os habitantes da África e das grandes cidades e o modo como se dão as relações de exploração entre eles. Teço, por fim, considerações finais mostrando a importância da reflexão constante sobre os diferentes artefatos culturais e o que eles estão ensinando.

\section{REPRESENTAÇÃO, PERFORMATIVIDADE E CINEMA}

o cinema é um marco na história cultural do ocidente (DUARTE, 2001). Ao longo dos seus mais de cem anos de existência, a possibilidade de contar histórias em movimento criou novos hábitos, instituiu celebridades, produziu valores culturais (LOURO, 2000). As histórias narradas, os personagens, a trilha sonora e outros elementos que compõem um filme têm influenciado toda uma geração de pessoas, cuja formação não pode ser dissociada do cinema (TEIXEIRA, 2005). Ainda que uma parcela significativa da população não tenha acesso direto a ele, não se pode esquecer que os filmes são posteriormente exibidos na televisão, tornando-se, assim, produtos de amplo consumo. Não se pode esquecer também que o cinema - notadamente o norteamericano - movimenta quantias vultosas de dinheiro, constituindo-se em uma das mais importantes indústrias da atualidade.

Os estudos culturais - campo teórico que emerge na Inglaterra no final dos anos 1950, tendo como objetivo problematizar a distinção, até então feita, entre "alta e baixa cultura" - têm procurado problematizar artefatos culturais como o cinema, considerando a implicação que ele tem na vida das pessoas. Há uma preocupação em tomar como objeto de estudo artefatos que atingem maior número de pessoas, pois eles, "sob a rubrica da diversão, do entretenimento e da fuga" (GIROUX, 1995, p. 136), colocam em circulação representações que atingem um contingente gigantesco de pessoas.

Nesse campo de estudos, a representação é entendida não como uma mera descrição da realidade ou como uma imagem do real e sim como constitutiva desse real, como produtiva, pois a representação constitui, produz e forma a "realidade" que aparentemente está apenas narrando. A representação constrói significados e sentidos que são atribuídos a uma dada situação, fazendo com que ela ganhe caráter de realidade. Nesse sentido, ela "inclui as práticas de significação e os sistemas simbólicos por meio dos quais os significados são produzidos, posicionandonos como sujeitos" (WOODWARD, 2009, p. 17). Assim, a realidade à qual temos acesso é elaborada por meio do sistema simbólico construído pela representação e nos coloca em determinadas posições de sujeito que nos permitem reconhecer algo como real.

Cabe registrar, porém, que as representações "não são um contraponto à realidade, não expressam seu reflexo ou seu falseamento" (LOURO, 2000, p. 444). Elas não encobrem, então, uma realidade ou um significado mais profundo. Pelo contrário, a representação é "sempre marca ou traço visível, exterior" (SILVA, 2009, p. 91). No processo de representação, a realidade vai sendo criada, "construída de acordo com os interesses dos grupos que exercem o poder" (SILVA, 1995, p. 198) naquele momento. Apesar de não expressar a realidade, uma representação será considerada tanto "mais real" quanto maior for a sua habilidade de apagar os "rastros que a ligam, discursivamente, ao 'real' e, portanto, em se expressar como o "real"” (SILVA, 1995, p. 199). A representação, nessa vertente, é, pois, um processo de produção de significados e sentidos por meio dos diferentes discursos. Assim, considero que os filmes, ao narrarem a África, contribuem para a construção de representações que ajudam na definição do que é o "real" acerca desse continente.

O conceito de representação pode ser vinculado ao de performatividade, que, por sua vez, pode ser definida "como a prática reiterativa e citacional pela qual o discurso produz os efeitos que ele nomeia" (BUTLER, 1999, p. 154). Para Butler, a força de uma determinada representação ou de um discurso advém de sua capacidade de ser citada em diferentes momentos, por diferentes artefatos, por diversos sujeitos. No que concerne à África, por exemplo, as representações ganham caráter de verdade por serem reconhecidas em diversos espaços e tempos. Os filmes fazem parte dessa longa cadeia discursiva que tem atuado na construção de representações sobre a África. Essa cadeia tem como característica principal o fato de poder ser citada, já que "a eficácia produtiva dos enunciados performativos ligados à identidade depende de sua incessante repetição" (SILVA, 2009, p. 94). Assim, os filmes repetem alguns enunciados divulgados nos mais diferentes espaços e meios, que, exatamente por isso, atuam na construção representações sobre o continente. 


\section{A NATUREZA AFRICANA: ENTRE O PARAÍSO PERDIDO E A SELVAGERIA}

O filme Madagascar 1 inicia com a imagem de uma bela paisagem: o sol nascendo no meio de coqueiros altos e grama verde. Atravessando essa paisagem, vemos uma zebra em um cipó. Uma música étnica ao fundo, enquanto a zebra grita: ohhhhh! Ela pula para outro cenário, ainda com os coqueiros e outras plantas. Pinguins cantam em coro: Livre! A zebra pula um penhasco, fazendo piruetas. De trás de uma moita, aparece um leão. A câmera se abre e vemos mais coqueiros e alguns baobás ao fundo. O leão pula na frente da zebra gritando: 'Surpresa'. Nesse momento, percebe-se que os animais não estão em uma floresta. A zebra encontra-se em uma esteira ergométrica, e o cenário é uma pintura na parede do zoológico de Nova York, onde vivem os dois animais. O filme Madagascar 2 começa de forma bastante semelhante, mostrando um vulcão ao fundo de uma savana, com algumas árvores, elefantes e girafas. Em seguida, vemos um leão tentando ensinar seu filhote a atacar outros animais. ${ }^{3}$

Lindas paisagens naturais: é assim que a África aparece na maior parte das cenas dos dois filmes aqui analisados. Em momento algum são mostradas paisagens africanas que não remetam aos ambientes que aprendemos a nomear como naturais. Grandes cidades e metrópoles aparecem somente nos Estados Unidos, especificamente em Nova York. Gomes (2008, p. 76) afirma que "nas imagens que são veiculadas sobre a África, raramente são mostrados os vestígios de um palácio real, de um império, as imagens de reis e muito menos as de uma cidade moderna". Essa parece ser a ideia que tais filmes veiculam. Neles, a África é identificada com a natureza.

A natureza nesses filmes é representada de duas formas principais. A primeira delas a apresenta como idílica, como paraíso perdido, como espaço de belezas jamais encontradas na civilização. A segunda mostra a natureza como perigosa e sorrateira. Nos dois casos, é possível perceber que natureza se opõe à civilização. A oposição civilização/natureza é um dos mais fortes binarismos de nossos tempos (KUNZRU, 2009). Por meio dela, simplifica-se o mundo, cindindo-o em dois polos e supervalorizando um deles. No caso dos filmes analisados, embora a maior parte da história se passe no cenário dito natural, a civilização é o espaço para o qual se almeja voltar. Essa civilização é representada pelos Estados Unidos, em oposição à África natural.

A representação da natureza como idílica está presente na cena descrita no início deste tópico. Nela é possível notar a visão idealizada segundo a qual a natureza é narrada. Ela aparece também quando a zebra Marty deseja como pedido de aniversário retornar para a natureza. Ela justifica esse seu desejo da seguinte forma: "Qual é! Imaginem poder voltar para a selva! De volta às raízes! Ar fresco, espaço aberto!” Ela também está presente quando, ao chegarem a um oásis após a queda de um avião em Madagascar 2, os personagens contemplam e têm o seguinte diálogo:

\author{
G: É muito lindo, não? \\ Ma: Arrebenta! \\ A: Pessoal, esse é o nosso lar!
}

A ideia da natureza como lar remete à busca pelas "características primitivas, originais, verdadeiras enfim, daquilo que tem sido configurado reiteradamente como relativo à essência da existência animal e animalhumana" (KINDEL, 2003, p. 50). Retornar à natureza, como deseja Marty, seria retornar a si mesmo, a um passado não corrompido, mais puro, no qual ainda não houve a intervenção do ser humano. Essa intervenção é, nesse caso, vista como negativa, já que a civilização é identificada como uma deturpação em relação ao natural. Cabe registrar, porém, que o artificial "nem sempre teve o tom pejorativo que atualmente lhe foi atribuído; consequentemente, nem sempre o natural foi tão fervorosamente pregado e vendido como na sociedade contemporânea" (AMARAL, 2004, p. 159. Grifo no original). Parece que, ao mesmo tempo em que há um distanciamento do dito natural no mundo atual, há uma crescente valorização desse natural perdido. Amaral (2004) mostra como essa valorização serve, entre outras coisas, para vender certos produtos que, ao se associarem ao natural, ganham um sobrevalor, passando a ser mais bem-vistos socialmente. Essa ideia está presente nos filmes quando, após se encantarem com a beleza da ilha, Marty afirma:

Ma: É igual! É igualzinho o mural do zoo! G: Não é não, querido! Isso aqui é de verdade!

É importante destacar, porém, que a definição do que é natural é uma construção social. Assim, quando nos filmes se apresenta o desejo de retornar à natureza, constrói-se aquilo que se considera como natureza. Essa definição não inclui, por exemplo, animais em cativeiro, já que os habitantes do zoológico de Nova York estão claramente fora da natureza. Não inclui também os seres humanos, pois o espaço natural se caracteriza pela ausência de pessoas. Como afirma o Rei Julian, habitante da ilha de Madagascar no primeiro filme, "se tivesse algum homem vivo por aqui, esse lugar não ia se chamar natureza". O ser humano não é apenas excluído do natural. Ele é apresentado como responsável por construir algo que não é a natureza. Percebe-se aqui uma oposição em relação à 
visão cartesiana que entende a natureza apenas naquilo que ela pode servir aos seres humanos. No contexto dos filmes, ela é representada como "espaço de inocência, como um lugar não corrompido, que segue leis próprias, que é regido pelas 'forças' do universo, sem a interferência do animal-homem" (KINDEL, 2003, p. 50-51).

Se, por um lado, a natureza aparece como "alheia, distinta, distante do cotidiano humano; como o 'outro' da cultura" (AMARAL, 2004, p. 146), por outro, ela pode ser representada também como perigosa e ameaçadora. Ser o oposto da civilização, nesse caso, é apresentado como algo negativo. Assim, quando param na ilha de Madagascar, ainda sem saber onde estão, os quatro animais entram na floresta e têm a seguinte conversa, em que é nítida a pouca valorização do espaço natural.

Me: Podia ter uma calçada!

G: Que coisa caída!

A: Deviam chamar isso aqui de zoo da esbórnia. Primeiro eles botam essa imensa área aberta para os bichos correrem livres. Daqui a pouco botam flores na sua cabeça e todo mundo fica dizendo paz e amor! - Enquanto andam, o leão pisa em espinhos, cai, se prende em uma teia de aranha, o que provoca pavor em todos, quando notam que a aranha ficou presa nele.

Essa cena demonstra que a natureza é desorganizada e assustadora. Nela não há os "luxos" aos quais os animais estavam acostumados no zoológico. Não há "comida refinada", "antibióticos" ou "médicos". A natureza é inóspita e assustadora. Ela é "anti-higiênica", como afirma Melman quando Marty deseja voltar para seu hábitat natural. Reafirma-se aqui a oposição entre natural e cultural, com a valorização do segundo elemento. Esse modo de conceber a natureza pode ser compreendido também como uma oposição a discursos ambientalistas contemporâneos que pregam "um retorno à natureza" (KINDEL, 2003, p. 160). Assim, ao mesmo tempo em que se valoriza a natureza como paraíso perdido, ela também é criticada porque esse paraíso não é estruturado como a civilização. Essa diferença no processo de representação evidencia como o mesmo não é unificado. Como afirma Woodward (2009, p. 14), "pode haver contradições no seu interior que têm que ser negociadas", ou seja, o processo de construção de representações não se dá sem conflitos, disputas e relações de poder. Um artefato cultural apresenta diferentes representações que atualizam aquilo que já tem sido dito, produzindo, em vez de significados unificados, multiplicidade de formas de representação.

A natureza também é perigosa por trazer à tona sentimentos de violência. Isso fica claro quando Alex, após viver algum tempo na ilha, passa a desejar comer todos os seus amigos. A natureza é capaz de despertar o lado selvagem do animal, fazendo com que ele ataque até mesmo aqueles que ama. Quando isso ocorre, a natureza não é mais apresentada no filme com as cores vivas e a variedade de espécies que marcam a primeira representação. Pelo contrário, os tons são sombrios, há cactos, pedras e despenhadeiros, sinalizando para a hostilidade que também pode ser percebida no espaço natural. Para resolver esse problema e equilibrar o seu lado carnívoro com as condições de vida na qual o leão está, a solução é apresentada pelos pinguins que passam a fazer sushis (uma comida "civilizada" e "refinada") para o personagem. Por meio da inserção em uma prática tida como cultural, o leão é capaz de controlar a sua própria natureza.

Controlar a natureza (seja externa, seja interior), tornando-a asséptica e o mais próxima possível da civilização, é o que o filme ensina ser necessário fazer. Essa representação tem suas bases na modernidade, quando a natureza "aparece como algo que deve ser reconstruído de forma a se ajustar às necessidades humanas" (KINDEL, 2003 , p. 50). Os dois filmes aqui analisados atualizam essa ideia, ensinando para os espectadores que esse é um modo aceitável de agir no espaço natural.

Ao reafirmar esse mito moderno de controle do natural, reafirma-se também a necessidade de controle do continente africano. Ainda que os filmes não ensinem isso explicitamente, é possível inferir tal ideia na medida em que o espaço africano é tido exclusivamente como natural. Por ser exclusivamente espaço da natureza, a África é associada ao não civilizado, ao primitivo. É preciso, então, garantir mecanismos de controle para esse espaço. Por meio desse processo, ignora-se que o espaço africano é "produzido pelas relações sociais ao longo da sua evolução histórica, suas desigualdades e contradições e a apropriação que esta e outras sociedades fizeram, e ainda o fazem, dos recursos da natureza (ANJOS, 2005, p. 174). A representação da África exclusivamente como natural serve como mecanismo para esquecimento da história de exploração e luta que se travou naquele continente. Por meio desse processo, tanto a natureza como o continente são desvalorizados e inferiorizados. Essas características se estendem aos seres que nele habitam, como mostro no tópico a seguir.

\section{AFRICANOS $\times$ NOVA-IORQUINOS: CIVILIZAÇÃo E BARBÁRIE?}

Logo que chegam em Madagascar, os quatro personagens principais do filme se deparam com os habitantes locais: são lêmures de diferentes espécies. Eles estão em uma espécie de rave, fazendo sons que remetem às músicas tribais e cantando a música 'Eu me remexo muito'. No meio deles, surge o Rei Julian com uma coroa de frutas na cabeça e falando: 'Aí, garotas de todo mundo, o Rei Julian original tá na 
área e tá bombando! Eu adoro garotas que gostam de mexer o corpo!' Essa festa causa espanto nos recémchegados, que travam o seguinte diálogo:

G: Gente, o que é isso?

Me: Eu já contei 26 violações à saúde pública!

Ao perceberem a presença dos estrangeiros, os lêmures se assustam e se questionam se eles são selvagens e irão atacá-los. Quando notam que isso não vai acontecer, o rei afirma:

J: Eles são só um bando de bocós!

Essa cena do primeiro contato entre habitantes da cidade e da ilha traz à tona algumas representações dos africanos e dos nova-iorquinos que perpassam todo o filme. A primeira delas é dos habitantes da África como exóticos, selvagens e estranhos. Isso se apresenta sobretudo na figura do Rei Julian. Ainda que ele seja um rei, o que difere de representações dos africanos que os associam às posições subalternas, trata-se de um rei bastante peculiar e exótico. Sempre falando alto e realizando movimentos exuberantes, Julian representa, no contexto do filme, o não civilizado. A sociedade apresentada na animação remete também ao tribal em detrimento do civilizado. Repetese, assim, a representação presente desde a Antiguidade, segundo a qual os povos da África "eram bárbaros - sem civilização - e identificados como trogloditas" (OLIVA, 2003, p. 443).

Esse significado se apresenta também quando a sociedade africana é apresentada como anti-higiênica, como visto na fala de Melman, ou quando Alex e o Rei Julian têm o seguinte diálogo, acerca da vida na natureza:

A: Natureza? Tipo, morando numa cabana de palha e limpando o traseiro em folha de bananeira?

J: Quem limpa? - ele ri e todos os outros lêmures também.

Associar a África à sujeira é algo tão forte em nossa sociedade que Oliva (2003, p. 430) relata um incidente envolvendo o ex-presidente Lula, que, em visita ao continente, afirmou estar surpreso por encontrar uma cidade tão limpa como Windhoek (capital da Namíbia). Os dois filmes aqui analisados repetem tal significado, reatualizando-o e auxiliando em sua manutenção para as novas gerações. Por meio do humor que tais situações carregam, age-se performativamente para ensinar, de modos suaves e muitas vezes mais interessantes do que aqueles propostos pela escola, como se organizam as sociedades nesse contexto.

Essa representação, porém, não se dá sem resistência. Isso fica evidente quando Julian afirma que os recémchegados são um "bando de bocós". É interessante observar que a postura dos locais não é de subserviência em relação aos citadinos. Pelo contrário, os habitantes pretendem utilizar certas habilidades dos animais recémchegados (particularmente o fato de o leão aterrorizar as fossas, animais que são predadores dos lêmures) para conseguir certos benefícios. Esse significado é diferente daquele que usualmente circula sobre a África. Ele pode ter como efeito uma problematização da submissão que supostamente haveria por parte dos africanos. Pode ser importante, por exemplo, para desconstruir significados sobre a escravidão, por mostrar que "os africanos não se deixaram escravizar" (CUNHA JR., 2007, p. 1), mas que foram e são ainda hoje ativos em seus modos de viver e de construir uma sociedade.

Outro modo de apresentar a sociedade africana está presente em Madagascar 2, particularmente no grupo que vive em um oásis na savana (e que também tem um rei, nesse caso, um leão). Essa sociedade é representada como organizada e harmônica. Se no outro caso o que se tinha era uma sociedade incivilizada, o que se tem aqui é mais uma vez a idealização da sociedade africana. Parece haver em certos momentos uma valorização dessas formas de organização social, repetindo o que se dava no movimento empreendido por historiadores, de supervalorização da África. Assim, as "civilizações africanas foram utilizadas como exemplo da capacidade de organização, transformação e produção africanas, que em nada ficavam a dever para os padrões europeus" (OLIVA, 2003, p. 440). Esse significado também aparece nos filmes, embora em menor proporção. Atrelada a ele, há a ideia de que a África é abundante em recursos naturais, particularmente em metais preciosos. Isso fica evidente na cena descrita a seguir:
A água do oásis é desviada e os animais se organi- zam para procurar novas fontes. Dois hipopótamos estão cavando, e um animal pergunta se eles acharam água:
G: Não! Só mais ouro e pedras preciosas! - Eles jogam um balde cheio de pedras preciosas, e os outros animais respondem com um penoso: Ahhhh!

O significado da África como espaço de riquezas pode ser, por um lado, compreendido como inserido na lógica de valorização desse continente. Afinal, lá haveria tanta riqueza que seus habitantes sequer ligariam para ela. Por outro lado, pode ser também uma atualização do significado de que "a África não disporia de qualquer outro papel além de área eternizada à função de provedora de bens e serviços apropriados para calcar o poderio dos próprios algozes" (SERRANO; WALDMAN, 2008, p. 23). Essa segunda ideia parece estar presente quando, no final do filme, dois pinguins se casam, conseguem reconstruir o avião e viajam em lua de mel. $\mathrm{Na}$ hora da 
despedida, um deles afirma: "A gente volta depois da lua de mel em Monte Carlo ou quando acabarem o ouro e os diamantes". A exploração do continente africano é apresentada aqui como algo natural e não problematizado pelos habitantes do local, que a aceitam sem maiores problemas.

Embora o foco dos filmes sejam os animais, cabe registrar a presença de alguns personagens humanos, sobretudo nas cidades, já que o único personagem humano aparentemente africano é um guia que leva nova-iorquinos por um passeio pelas savanas africanas em Madagascar 2. Ele é apresentado como alguém que, apesar de ser nativo, não sabe se comportar na selva. Quando o grupo é obrigado pelos pinguins a pernoitar na floresta, quem toma a frente para resolver a situação não é ele, mas uma idosa de Nova York, que estava realizando o passeio. O filme trabalha com o significado de que os africanos são desnecessários até mesmo para garantir a sobrevivência em seu território.

Associada a esse significado, a África nesse momento do filme aparece atrelada a "uma imagem hostil dos trópicos, cheios de forças naturais adversas ao colonizador europeu e de homens ditos indolentes" (ANJOS, 2005, p. 175). Os personagens da cidade têm grande dificuldade em lidar com essa diferença, e um deles, gravando um vídeo, afirma não ver nenhum sinal de civilização. Apenas a senhora idosa mantém o ânimo e faz um discurso para incentivar a todos, que estão desesperados pela ausência de comida, água ou fogo:

I: Vocês podem deixar a natureza se aproveitar de vocês ou vocês podem se aproveitar da natureza. Cheguem mais perto, crianças! Somos nova-iorquinos, não somos? Sobrevivemos naquela selva de concreto! Quando temos fome, caçamos um belo cachorroquente. Se precisamos de abrigo, construímos arranhacéus. E se precisamos de água, nós fazemos um dique! Se a gente venceu lá, pode vencer em qualquer lugar!" Após o discurso, as pessoas perdidas afirmam: 'Somos de Nova York! A gente pode tudo'.

A cena acima evidencia alguns aspectos já discutidos aqui, tais como a visão utilitária em relação à natureza e da África como um ambiente inóspito. Porém, ela traz também a representação das pessoas da cidade como superiores às pessoas que habitam outras regiões. Em função do uso da tecnologia e da capacidade de manipular o meio, essas pessoas são representadas como mais capazes. Elas podem qualquer coisa, como evidencia a cena anterior. Nesse sentido, justifica-se que aqueles que vivem em grandes metrópoles não são apenas melhores, mas também podem subjugar quem habita outros espaços. Repete-se nos filmes analisados a atribuição de um significado superior aos citadinos ocidentais em relação aos de outros locais. No que se refere à África, essa noção de superioridade justificou uma série de abusos cometidos no continente. Os filmes, ao operarem com esse binarismo, naturalizam a situação e tratam de mantêla tal qual ela está.

Cabe registrar, porém, que o filme, ao representar a África dessa maneira, produz um saber ocidental sobre ela. Como argumenta Woodward (2009, p. 24), esse saber "diz mais sobre os medos e ansiedades ocidentais do que sobre a vida no Oriente e na África do Norte". Se pensarmos com base em uma perspectiva pós-colonial, essas narrativas sobre a África construídas nos filmes de animação mostram o medo ocidental em relação àquilo que se produziu como diferente e representam uma tentativa de manter as relações de poder da forma como elas se estabeleceram historicamente. Assim, citar perfomaticamente as representações de superioridade branca, ocidental, citadina, trata-se de uma estratégia para manutenção de relações de hierarquia constituídas ao longo dos séculos.

\section{EFEITOS DA PEDAGOGIA CULTURAL NAS REPRESENTAÇÕES DA ÁFRICA}

como demonstrado ao longo do artigo, os dois filmes selecionados para análise se envolvem diretamente na manutenção de representações sobre a África que se opõem àquilo que o currículo oficial brasileiro tem tentado implementar desde a promulgação da Lei $10639 / 2003$. Se considerarmos que esses filmes estão presentes no contexto escolar, cabe-nos problematizar o que eles têm ensinado para os espectadores. Refletir sobre isso é importante no contexto das escolas, já que muitas vezes assistimos a esses filmes desconsiderando seu potencial educativo e sua influência na construção de representações de variados assuntos.

Nesses momentos, operamos uma naturalização desses materiais, como se eles fossem inocentes e neutros. Somos envolvidos pelas belas imagens, pela trilha sonora bem selecionada, pelo humor e pelo divertimento e não problematizamos esses materiais. Porém, todo processo de naturalização envolve a manutenção das desigualdades. É justamente o entendimento de que os filmes e as representações da África (e também de gênero, sexualidade, raça/etnia, religião, geração, entre outros) são construídas socialmente que nos permite modificálas. Afinal, se essas representações não são naturais, mas construídas, elas podem ser problematizadas e reconstruídas constantemente. Para isso, é necessário termos um olhar atento e crítico para artefatos culturais que aparentemente são neutros, mas que estão ativamente envolvidos nos modos como entendemos a nós mesmos e ao mundo. 


\section{REFERÊNCIAS}

AMARAL, Marise. Natureza e representação na pedagogia da publicidade. In: COSTA, Marisa Vorraber. Estudos culturais em educação. 2. ed. Porto Alegre: Editora da UFRGS, 2004.

ANJOS, Roberto. A geografia, a África e os negros brasileiros. In: MUNANGA, Kabengele (Org.). Superando o racismo na escola. 2. ed. Brasília: MEC, 2005.

BALESTRIN, Patrícia; SOARES, Rosângela. "Etnografia da tela": uma aposta metodológica. In: MEYER, Dagmar; PARAISO, Marlucy. Metodologias de pesquisas pós-críticas em educação. Belo Horizonte: Mazza, 2012.

BUTLER, Judith. Corpos que pesam: sobre os limites discursivos do sexo. In: LOURO, Guacira. O corpo educado: Pedagogias da Sexualidade. Belo Horizonte: Autêntica, 1999.

CUNHA JR., Henrique. Os negros não se deixaram escravizar: temas para as aulas de história dos afrodescendentes. Revista Eletrônica Espaço Acadêmico, v. 69, p. 1-10, 2007. Disponível em: <http://www.espacoacademico.com.br/069/69 cunhajr.htm>.

DUARTE, Rosália. Cinema e educação. Belo Horizonte: Autêntica, 2001.

GIROUX, Henry. Memória e pedagogia no maravilhoso mundo da Disney. In: SILVA, Tomaz Tadeu da. Alienígenas na sala de aula: uma introdução aos estudos culturais em educação. Petrópolis: Vozes, 1995.

GOMES, Nilma. A questão racial na escola: desafios colocados pela implementação da Lei 10639/2033. In: MOREIRA, Antonio Flavio; CANDAU, Vera. Multiculturalismo: diferenças culturais e práticas pedagógicas. Petrópolis: Vozes, 2008.

KINDEL. Eunice. A natureza no desenho animado: ensinando sobre homem, mulher, raça, etnia e outras coisas mais. 2003. Tese (Doutorado em Educação) - Faculdade de Educação, Universidade Federal do Rio Grande do Sul, Porto Alegre, 2003.

KUNZRU, Hari. "Você é um ciborgue": um encontro com Donna Haraway. In: HARAWA, Donna; KUNZRU, Hari; TADEU, Tomaz. Antropologia do ciborgue: as vertigens do pós-humano. Org. e trad. de Tomaz Tadeu. 2. ed. Belo Horizonte: Autêntica, 2009.

LOURO, Guacira Lopes. O cinema como pedagogia. In: LOPES, Eliana Marta Teixeira; FARIA FILHO, Luciano Mendes; VEIGA, Cynthia Greive (Org.). 500 anos de educação no Brasil. Belo Horizonte, Autêntica, 2000.

OLIVA, Anderson. A história da África nos bancos escolares. Representações e imprecisões na literatura didática. Estudos Afro-Asiáticos, ano 25, n. 3, 2003.
OLIVA, Anderson. A história africana nas escolas brasileiras: entre o prescrito e o vivido, da legislação educacional aos olhares dos especialistas (1995-2006). História, Franca, v. 28, n. 2, 2009.

RIAL, Carmen. Estudos de mídia. In: GROSSI, Miriam (Org.). Movimentos sociais, educação e sexualidades. Rio de Janeiro: Garamond, 2005.

SERRANO, Carlos; WALDMAN, Maurício. Memória d'África: a temática africana em sala de aula. 2. ed. São Paulo: Cortez, 2008.

SILVA, Tomaz Tadeu. Currículo e identidade social: territórios contestados. In: (Org.). Alienígenas na sala de aula: uma introdução aos estudos culturais em educação. Petrópolis: Vozes, 1995.

SILVA, Tomaz Tadeu. Documentos de identidade: uma introdução às teorias do currículo. Belo Horizonte: Autêntica, 2001

SILVA, Tomaz Tadeu. A produção social da identidade e da diferença. In: . (Org.). Identidade e diferença: a perspectiva dos estudos culturais. Petrópolis: Vozes, 2009.

STEINBERG, Shirlei. Kindercultura: a construção da infância pelas grandes corporações. In: SILVA, Luiz Heron et al. Identidade social e a construção do conhecimento. Porto Alegre: Secretaria Municipal de Educação, 1997.

TEIXEIRA, Inês. Apresentação à Seção Temática: Cinema e Educação. Educação em Revista, Belo Horizonte, v. 41, jun. 2005.

WOODWARD, Kathryn. Identidade e diferença: uma introdução teórica e conceitual. In: SILVA, Tomaz Tadeu (Org.). Identidade e diferença: a perspectiva dos estudos culturais. Petrópolis: Vozes, 2009.

\section{NOTAS}

1 Informação disponível em <http://pt.wikipedia.org/wiki/Anexo:Lista de_filmes_de_maior_bilheteria>. Acesso em: 16 abr. 2013.

2 O terceiro filme não foi analisado por dois motivos: sua história não se passa inteiramente na África e foi lançado após o encerramento desta pesquisa.

3 Para diferenciar as falas e cenas dos filmes que serão destacadas, elas são apresentadas com recuo em relação à margem do texto normal. Utilizarei $\mathrm{a}$ (s) letra(s) inicial(is) do nome dos animais para diferenciá-los quando estão conversando. Assim, o G significa uma fala do personagem Glória; A significa Alex; Ma, Marty; Me, Melman; I, idosa; J, Jullian.

Artigo recebido em janeiro 2014.

Aprovado em maio 2014. 